\title{
A RELIGIÃO NAS ELEIÇÕES 2006 NO RIO GRANDE DO SUL: O QUE HÁ DE NOVO?
}

\author{
Ari Pedro Oro* \\ Rosilene Schoenfelder
}

Resumo: Este texto efetua um balanço geral da presença de candidatos a cargos eletivos nas eleições de 2006, no Rio Grande do Sul, que se apresentaram publicamente enquanto religiosos ou representantes, oficiais ou não, de instituições religiosas. $\mathrm{O}$ texto está dividido em duas partes. A primeira efetua uma ampla apresentação dos candidatos das diferentes instituiçôes religiosas que compareceram ao pleito eleitoral de 2006, e a segunda procede a uma comparação destacando as principais recorrências e as singularidades observadas no pleito atual em relação aos demais, ocorridos nos últimos anos.

Palavras-chave: religião, política, Rio Grande do Sul, eleições 2006.

Principalmente após o retorno da democracia, a cada nova eleição que ocorre no país, sejam elas majoritárias ou proporcionais, assistimos a presença de candidatos a cargos eletivos, sobretudo para os legislativos, que reivindicam e afirmam a sua condição de agentes ou líderes religiosos - sejam eles pastores, bispos, padres, pais-de-santo, ou outro - ou, então, de membros de instituições religiosas que expõem abertamente os seus vínculos religiosos por ocasião da campanha eleitoral. Também já é aceito com naturalidade o fato dos candidatos em geral a cargos eletivos se aproximarem dos grupos religiosos, sobretudo das igrejas evangélicas, dos afro-brasileiros e dos espíritas, nos períodos que antecedem as eleições.

Esse quadro se reproduziu nas eleições majoritárias de 2006, ocasião em que acompanhamos a inserção de igrejas e de candidatos religiosos ou outros que explicitaram o seu vínculo religioso durante a campanha eleitoral no Rio Grande do Sul. A observação ocorreu mediante o acompanhamento dos programas eleitorais gratuitos no rádio e na televisão, a análise do material de campanha dos candidatos e a inserção etnográfica em diferentes lugares religiosos, para ver o espaço reservado ao momento político eleitoral. Assim sendo, este texto procura mostrar como se deu a presença do religioso no político institucional no Rio Grande do Sul, por ocasião das eleiçōes de outubro de 2006. Também será dada atenção especial à percepção das situações recorrentes nestas eleições em relação às demais e das especificidades aparecidas nesta última eleição no que concerne o objeto referido.

* Professor do Departamento de Antropologia e do Programa de Pós-Graduação em Antropologia Social da UFRGS e pesquisador do CNPq.

** Estudante de graduação do Curso de Ciências Sociais da UFRGS e bolsista BIC/UFRGS do Núcleo de Estudos da Religião (NER). 
Este texto está dividido em duas partes. A primeira apresenta os diferentes candidatos oriundos das várias denominaçóes religiosas que se apresentaram, no Rio Grande do Sul, a cargos eletivos para deputado estadual e federal. Ver-se-á seus vínculos religiosos institucionais, seus vínculos partidários, o número de votos alcançados e seus pronunciamentos no horário eleitoral. A segunda realiza um olhar comparativo com as eleiçôes de 2002 colocando em evidência as principais recorrências e destacando as principais especificidades verificadas nas eleiçōes atuais ${ }^{1}$.

\section{RELIGIÃO E ELEIÇÕES 2006 NO RIO GRANDE DO SUL: OS NOMES E OS NÚMEROS}

Inicialmente, vale informar que no Rio Grande do Sul candidataram-se 490 pessoas para as 55 cadeiras de deputado estadual e 279 candidatos para as 31 vagas gaúchas para a Câmara Federal. Entre os primeiros, 31 candidatos, ou seja, 6,3\% do total, expressaram a sua identificação religiosa, enquanto que entre os segundos, 14 candidatos, isto é, 5,0\%, afirmaram semelhante condição, ou seja, um vínculo institucional religioso. No total são ao menos 45 candidatos que compareceram ao pleito de 2006 no Rio Grande do Sul na condição de líderes religiosos ou de membros declarados de denominações religiosas, contando, de alguma forma, capitalizar eleitoralmente por esse viés.

A tabela a seguir apresenta uma visão panorâmica do número de candidatos que durante o pleito de 2006 expressaram abertamente a sua condição religiosa ou que, de alguma forma, inseriram-se no político institucional, isto é, partidário-eleitoral, acionando a sua vinculação a determinados segmentos religiosos.

Tabela I - Visão geral dos candidatos religiosos no Rio Grande do Sul

\begin{tabular}{|c|c|c|c|c|c|c|c|}
\hline $\begin{array}{c}\text { Denominação } \\
\text { Religiosa }\end{array}$ & \multicolumn{2}{|c|}{ Deputado Estadual } & \multicolumn{3}{c|}{ Deputado Federal } & $\begin{array}{c}\text { Total } \\
\text { Geral }\end{array}$ \\
\hline & $\begin{array}{c}\text { Líder } \\
\text { Religioso }\end{array}$ & Membro & Total & $\begin{array}{c}\text { Líder } \\
\text { Religioso }\end{array}$ & Membro & Total & \\
\hline $\begin{array}{c}\text { Assembléia } \\
\text { de Deus }\end{array}$ & 3 & 6 & 9 & 3 & 3 & 6 & 15 \\
\hline $\begin{array}{c}\text { Igreja } \\
\text { Universal }\end{array}$ & 2 & 1 & 3 & 1 & - & 1 & 4 \\
\hline Quadrangular & 2 & - & 2 & 2 & 1 & 3 & 5 \\
\hline
\end{tabular}

\footnotetext{
${ }^{1}$ A inserção política de algumas expressões religiosas, bem como de candidatos religiosos, nas eleiçôes de 2006 no Rio Grande do Sul, como as igrejas evangélicas e as religióes afro-brasileiras, será aprofundada em outros artigos que figuram no presente volume de Debates do NER.
} 


\begin{tabular}{|c|c|c|c|c|c|c|c|}
\hline $\begin{array}{c}\text { Internacional } \\
\text { da Graça }\end{array}$ & 1 & 1 & 2 & - & - & - & 2 \\
\hline $\begin{array}{c}\text { Pentecostal } \\
\text { Cristã }\end{array}$ & 1 & 1 & 2 & - & - & - & 2 \\
\hline $\begin{array}{c}\text { Apostólica } \\
\text { do Brasil }\end{array}$ & - & 1 & 1 & - & - & - & 1 \\
\hline $\begin{array}{c}\text { Brasil para } \\
\text { Cristo }\end{array}$ & 1 & - & 1 & - & - & - & 1 \\
\hline $\begin{array}{c}\text { Sara Nossa } \\
\text { Terra }\end{array}$ & 1 & - & 1 & 1 & - & 1 & 2 \\
\hline Adventista & 1 & - & 1 & - & - & - & 1 \\
\hline $\begin{array}{c}\text { Confissão } \\
\text { luterana }\end{array}$ & 1 & - & 1 & - & - & - & 1 \\
\hline $\begin{array}{c}\text { Batista } \\
\text { Filadélfia }\end{array}$ & - & 1 & 1 & - & - & - & 1 \\
\hline Batista & - & 1 & 1 & - & - & - & 1 \\
\hline Batista Betel & - & - & - & - & 1 & 1 & 1 \\
\hline Presbiteriana & - & 1 & 1 & - & - & - & 1 \\
\hline Afro-religiosos & 1 & 1 & 2 & - & - & - & 2 \\
\hline Católicos & 1 & - & 1 & - & 1 & 1 & 2 \\
\hline Outros & 1 & 1 & 2 & 1 & - & 1 & 3 \\
\hline Total & & & 31 & & & 14 & 45 \\
\hline
\end{tabular}

Nota-se, inicialmente, a predominância absoluta de candidatos a cargos eletivos de indivíduos pertencentes ao campo evangélico, sobretudo representantes de igrejas do segmento pentecostal e neo-pentecostal. Em seguida, comparecem os representantes do campo religioso afro-brasileiro e católico. Os "outros", que figuram na tabela, situam-se também no campo evangélico, mas sua denominação nos escapa. Dessa forma, como se pode notar, nem todas as expressões religiosas que configuram o pluralismo religioso local se fizeram explicitamente presente no principal momento político de 2006. É o caso do espiritismo, do judaísmo, do islamismo e de outras correntes religiosas minoritárias.

Por outro lado, pode-se ver nessa tabela a reprodução de determinados elementos já observados em outras eleições, sejam elas majoritárias ou proporcionais. Em primeiro lugar, a Assembléia de Deus - igreja evangélica que detém o maior número de fiéis, tanto a nível nacional quanto regional - é a instituição religiosa que teve o maior número de candidatos a cargos eletivos: 9 para deputado estadual e 6 para deputado federal, totalizando 15 candidatos $^{2}$. Seguem as duas outras denominações evangélicas que também já detém

${ }^{2}$ Como o leitor poderá notar, os números aqui apresentados nem sempre coincidem plenamente com aqueles propostos por Mariano em seu artigo que também figura neste volume. Tais incongruências, porém, não chegam a afetar as análises constantes em ambos os textos.

Debates do NER, Porto Alegre, ano 7, N. 10, p. 7-26, jul./Dez. 2006 
uma certa importância histórica no processo político eleitoral regional, a saber: as igrejas Universal do Reino de Deus e Evangelho Quadrangular, ambas com 5 candidatos cada uma. Em segundo lugar, desde já adiantamos que o baixo número de representantes a cargos eletivos provenientes dos meios católico e afro-brasileiro deve-se, sobretudo, no que concerne ao primeiro caso, a uma posição há muito tempo assumida pela Igreja Católica no Brasil de não participar diretamente do político institucional, desaconselhando mesmo as candidaturas de membros do clero; já relativamente ao campo religioso afro-brasileiro, a reduzida presença de seus membros candidatos a cargos eletivos advém de dificuldades inerentes ao próprio campo religioso (Prandi, 1991). Enfim, reiteramos algo já observado em outros pleitos eleitorais: é de longe muito mais significativa a presença de candidatos a deputados oriundos do segmento evangélico pentecostal do que do segmento evangélico histórico.

Por outro lado, porém, essa mesma tabela apresenta uma importante novidade, ao menos relativamente ao Rio Grande do Sul. Nunca houve uma diversificação evangélica tão acentuada de candidatos a cargos eletivos para a Assembléia legislativa e para a Câmara Federal como a agora observada. Ou seja, além das igrejas evangélicas tradicionais, históricas e pentecostais, desta feita compareceram candidatos representantes ou membros de igrejas como Internacional da Graça de Deus, Sara Nossa Terra, Evangélica Pentecostal Cristã e Brasil para Cristo.

\section{Candidatos Evangélicos À Assembléia LegisLativa}

Como mostrou a tabela I, compareceram 28 candidatos a deputado estadual representando o segmento evangélico e 13 candidatos a deputado federal do mesmo ramo religioso. Como veremos, os primeiros obtiveram, juntos, 198.248 votos, sendo 150.810 obtidos por candidatos de igrejas pentecostais e 47.438 por candidatos de igrejas históricas. Posto que, segundo o Tribunal Regional Eleitoral do Rio Grande do Sul, o total de votos válidos para deputado estadual foi de 5.997.049, os evangélicos, ao menos os que constam no repertório obtido em nossa pesquisa, amealharam 3,3\% do total dos votos válidos. Já os evangélicos que disputaram vaga para a Câmara Federal obtiveram 192.811 votos, o que representa 3,2\% sobre o total de votos válidos destinados a deputados federais no Estado do Rio Grande do Sul, que foi de 5.962.088.

\section{Candidatos Evangélicos Pentecostais à Assembléia Legislativa}

Vejamos agora mais detalhadamente como foi o desempenho, nas eleições de 2006, dos candidatos evangélicos pentecostais para a Assembléia legislativa do Estado do Rio Grande do Sul. 
Tabela II - Candidatos Evangélicos Pentecostais - Assembléia Legislativa

\begin{tabular}{|c|c|c|c|c|c|}
\hline Denominação & Nome & Função & Partido & Votos & Situação \\
\hline $\begin{array}{c}\text { Assembléia } \\
\text { de Deus }\end{array}$ & Edemar Vargas & Pastor & РTB & 14.284 & Não-eleito \\
\hline $\begin{array}{l}\text { Assembléia } \\
\text { de Deus }\end{array}$ & João de Deus & Pastor & PTB & 5.340 & Não-eleito \\
\hline $\begin{array}{c}\text { Assembléia } \\
\text { de Deus }\end{array}$ & Roberto Santos & Pastor & PHS & 173 & Não-eleito \\
\hline $\begin{array}{l}\text { Assembléia } \\
\text { de Deus }\end{array}$ & $\begin{array}{l}\text { Atacilho } \\
\text { Fortunato }\end{array}$ & Evangelista & PP & 2.453 & Não-eleito \\
\hline $\begin{array}{c}\text { Assembléia } \\
\text { de Deus }\end{array}$ & $\begin{array}{c}\text { Gelson } \\
\text { Domingues }\end{array}$ & Presbítero & PSDC & 286 & Não-eleito \\
\hline $\begin{array}{c}\text { Assembléia } \\
\text { de Deus }\end{array}$ & Valdir Roxo & Presbítero & PTB & 4.423 & Não-eleito \\
\hline $\begin{array}{l}\text { Assembléia } \\
\text { de Deus }\end{array}$ & $\begin{array}{c}\text { Willes } \\
\text { Taranger }\end{array}$ & Membro & PSC & 9.477 & Não-eleito \\
\hline $\begin{array}{l}\text { Assembléia } \\
\text { de Deus }\end{array}$ & Lair Nunes & Membro & PAN & 590 & Não-eleito \\
\hline $\begin{array}{c}\text { Assembléia } \\
\text { de Deus }\end{array}$ & $\begin{array}{l}\text { Cláudio } \\
\text { M. Lopes }\end{array}$ & Membro & РTB & 4.978 & Não-eleito \\
\hline $\begin{array}{c}\text { Total de Votos } \\
\text { Assembléia } \\
\text { de Deus }\end{array}$ & & & & 42.004 & \\
\hline Universal & Carlos Gomes & Pastor & PPS & 66.454 & Eleito \\
\hline Universal & Sueli de Jesus & Evangelista & PTB & 210 & Não-eleito \\
\hline Universal & Sérgio Peres & Pastor & PL & 22 & Não-eleito \\
\hline $\begin{array}{c}\text { Total de votos } \\
\text { Universal }\end{array}$ & & & & 66.686 & \\
\hline Quadrangular & $\begin{array}{l}\text { Uberani } \\
\text { Barbosa }\end{array}$ & Pastor & PTB & 15.474 & Não-eleito \\
\hline Quadrangular & Rogério Santos & Pastor & PTB & 5.864 & Não-eleito \\
\hline $\begin{array}{l}\text { Total de votos } \\
\text { Quadrangular }\end{array}$ & & & & 21.338 & \\
\hline $\begin{array}{c}\text { Internacional } \\
\text { da Graça } \\
\text { de Deus }\end{array}$ & Adelar Bayer & Membro & РTB & 8.416 & Não-eleito \\
\hline $\begin{array}{c}\text { Internacional } \\
\text { da Graça } \\
\text { de Deus }\end{array}$ & $\begin{array}{l}\text { Vanderlei } \\
\text { Feltrin }\end{array}$ & Pastor & PV & 253 & Não-eleito \\
\hline $\begin{array}{l}\text { Total de votos } \\
\text { Internacional }\end{array}$ & & & & 8.669 & \\
\hline
\end{tabular}

Debates do NER, Porto Alegre, ANo 7, N. 10, P. 7-26, Jul./DeZ. 2006 


\begin{tabular}{|c|c|c|c|c|c|}
\hline $\begin{array}{c}\text { Pentecostal } \\
\text { Cristã }\end{array}$ & $\begin{array}{c}\text { Volmar } \\
\text { dos Santos }\end{array}$ & Bispo & PSDB & 5.990 & Não-eleito \\
\hline $\begin{array}{c}\text { Apostólica } \\
\text { do Brasil }\end{array}$ & Irmão Osmar & Membro & PAN & 345 & Não-eleito \\
\hline $\begin{array}{c}\text { Brasil } \\
\text { para Cristo }\end{array}$ & Olnei Gomes & Pastor & PSB & 3.275 & Não-eleito \\
\hline $\begin{array}{c}\text { Sara nossa } \\
\text { Terra }\end{array}$ & Almir Guedes & Pastor & PL & 2.503 & Não-eleito \\
\hline $\begin{array}{c}\text { Total outras } \\
\text { Pentecostal }\end{array}$ & & & & 12.113 & \\
\hline $\begin{array}{c}\text { Total Geral } \\
\text { Pentecostal }\end{array}$ & & & & 150.810 & \\
\hline
\end{tabular}

A tabela mostra que das três principais igrejas pentecostais que comparecem há alguns anos no político institucional, brasileiro e regional, a Universal do Reino de Deus foi a instituição que obteve o maior número de votos, totalizando 66.686. Segue a Assembléia de Deus com 42.004 votos e a igreja Quadrangular, com 21.338 votos. Das outras igrejas, a mais representativa foi a Internacional da Graça de Deus, com 8.669 votos, seguida da Igreja Evangélica Pentecostal Cristã, com 5.990 votos, da igreja Brasil para Cristo, com 3.275 votos, da Sara Nossa Terra, com 2.503 votos e da Igreja Apostólica do Brasil, com 345 votos.

Nota-se também que somente 1 , entre os 20 candidatos pentecostais, logrou ser eleito como deputado estadual no Rio Grande do Sul. Trata-se do pastor Carlos Gomes, da Igreja Universal do Reino de Deus. Nenhum dos demais candidatos alcançou nem mesmo alguma suplência para deputado em alguma legenda ou partido.

Vamos agora nos ater, mais especificamente, a cada uma das denominaçóes pentecostais.

A Igreja Universal centralizou seu investimento político na eleição de Carlos Gomes e, como já demonstrou em outras oportunidades no Rio Grande do Sul, obteve êxito mais uma vez. Ele debuta na política e é pastor da igreja em Porto Alegre. Obteve 66.454 votos. Em suas aparições no horário da propaganda eleitoral gratuita no rádio e na televisão não mencionava o fato de ser pastor nem de ser membro da Igreja Universal. Reproduzia um discurso vulgarizado em tempos de campanha. Dizia ele: "Vou lutar pela inclusão social, por mais emprego, educação de qualidade e capacitação". E finalizava dizendo: "Vote pela renovação".

Nas eleições de 2002 a Universal havia eleito outro pastor, que também debutava na política: Sergio Peres, que havia obtido 46.652 votos. Na campanha atual a opção da Igreja foi pelo candidato hoje vencedor. Sergio Peres, por sua vez, chegou a registrar a sua candidatura a deputado estadual pelo PTB, mas ao longo da campanha desistiu da mesma, embora seu nome tivesse permanecido como candidato. Dedicou-se à eleição de Carlos Gomes e por isso obteve 22 votos. Ainda compareceu no horário eleitoral gratuito no 
rádio e na televisão Sueli de Jesus, que se dizia evangelista da Igreja Universal ${ }^{3}$. Não tendo sido apoiada pela igreja obteve somente 210 votos.

A Assembléia de Deus tinha historicamente um seu representante como deputado estadual. De fato, Edemar Vargas concorria ao seu quinto mandato e por ocasião da propaganda no rádio e na televisão se dizia "deputado dos evangélicos e representante da Igreja Assembléia de Deus”. Nas eleiçōes de 2002 havia obtido 49.577 votos ${ }^{4}$. Edmar Vargas trabalhou em empresas privadas durante 16 anos antes de ingressar na política, como deputado. Converteu-se à Assembléia de Deus aos 15 anos de idade, na cidade de Tupaciretã, RS, onde morou até os 22 anos. Ao chegar à capital tornou-se líder da juventude assembleiana, depois primeiro secretário, em seguida presbítero, diácono, evangelista, e ultimamente pastor. É formado em Direito.

Mas desta feita, diferentemente das demais, obteve uma votação insuficiente para ser eleito (14.284), resultado de situaçôes específicas envolvendo a sua própria atividade parlamentar, da concorrência que enfrentou com os demais candidatos egressos da própria igreja que também postulavam uma cadeira na Assembléia legislativa e de um certo desencanto em relação à política que predomina no momento no âmbito dessa igreja.

Entre os candidatos a deputado estadual da Assembléia de Deus compareceu outro pastor, que já tem uma trajetória na política. Trata-se do Pastor João de Deus, que já exerceu o cargo de deputado federal entre os anos de 1987 a 1991 e 1991 a 1995, sendo acusado de participar da "máfia dos Anôes". No entanto, em suas inserções de poucos segundos, por ocasião da propaganda eleitoral gratuita no rádio e na televisão, não lembrou a sua condição de ex-deputado federal. Acionou a sua situação de delegado de política e de pastor, centrando seus dizeres no tema da segurança. Disse ele: "Somos reféns de um sistema paralelo que nos oprime e nos amedronta. Com Rigotto vamos mudar as regras dessa situação cruel e arbitrária fazendo mais pela segurança. Vote no delegado de polícia”.

Outro candidato que já fez tentativas de ingressar na política é Willis Taranger, engenheiro e filho do renomado pastor sueco Nils Taranger, um dos fundadores da Assembléia de Deus do Rio Grande do Sul (Oro, 2001, pp. 31-32; Stein, 1998). Candidato a vereador no ano 2000 obteve 2.491 votos, não tendo sido eleito. Em seu pronunciamento no horário eleitoral gratuito não vinculou seu nome à Assembléia de Deus mas sim ao cristianismo. Disse ele: "Na defesa de entidades sociais, e por um Rio Grande mais social e mais cristão".

Por seu turno, Cláudio Lopes exerce a atividade de vereador em Nova Santa Rita. Em seu pronunciamento no horário eleitoral, além de recordar esta sua condiçáo política, dizia:

\footnotetext{
${ }^{3}$ Dizia ela: "Evangelista da Igreja Universal, defensora dos direitos dos deficientes. Lutarei pela criaçáo de empregos e redução de impostos".

${ }^{4}$ Edmar Vargas trabalhou em empresas privadas durante 16 anos antes de ingressar na política, como deputado. Converteu-se à Assembléia de Deus aos 15 anos de idade, na cidade de Tupaciretã, RS, onde morou até os 22 anos. Ao chegar à capital tornou-se líder da juventude assembleiana, depois primeiro secretário, em seguida presbítero, diácono, evangelista, e ultimamente pastor. É formado em Direito.
}

Debates do NER, Porto Alegre, Ano 7, N. 10, P. 7-26, Jul./Dez. 2006 
"sou evangélico, professor, oficial de justiça. Vou lutar contra as altas mensalidades das faculdades acessíveis a poucos. Busco mais incentivo para agricultura familiar e setor calçadista”.

Os demais candidatos da Assembléia de Deus, ao que parece, estariam debutando na política. Roberto Santos dizia-se, no horário eleitoral, pastor e recordava o fato de ter sido menino de rua. Propunha combater a corrupção. Atacilho Furtu nato dizia-se evangelista, nestes termos: "Como evangelista da Assembléia de Deus peço seu apoio". Lair Nunes dirigia-se aos "aposentados e evangélicos (...) Preciso da tua ajuda”. Enfim, dois candidatos se apresentavam como candidatos evangélicos com a intenção de buscar benefícios para esse segmento sócio-religioso. Gelson Domingues falava em hospital e universidade evangélicos , e Valdir Roxo, vereador na cidade de Xangrilá, na "construção de um hospital regional no litoral", suben tende-se para os evangélicos, pois, dizia ele, no horário eleitoral: "Minha luta é pelo povo evangélico".

A Igreja do Evangelho Quadrangular, por sua parte, também não elegeu nenhum dos dois candidatos que afirmavam a sua vinculação religiosa com esta instituição religiosa. O pastor Uberani Barbosa, que se dizia candidato indicado pela igreja ${ }^{6}$, foi o mais votado, seguido de Rogério Santos, este sendo filho do deputado e pastor da Igreja Quadrangular Manoel Maria ${ }^{7}$ Este último, após ter sido eleito por três legislaturas como candidato apoiado pela Igreja, tendo obtido 38.361 votos nas eleiçóes de 2002, desistiu de concorrer neste ano, apresentando em seu lugar seu filho como candidato, para quem, como se vê, não ocorreu a transferência de votos. Consequentemente, a Quadrangular, bem como a Assembléia de Deus, não terão representantes no legislativo estadual no período 2007-2010.

Como dizíamos acima, é novidade no Rio Grande do Sul o fato de representantes de outras igrejas pentecostais, aqui detentoras de menor número de fiéis do que as igrejas acima referidas, também comparecerem no pleito eleitoral. É o caso da Igreja Internacional da Graça de Deus, cujo membro, Adelar Bayer, obteve 8.416 votos, além dos 253 votos obtidos por outro membro da igreja, Vanderlei Feltrin. Importa frisar que Adelar Bayer foi durante 13 anos pastor da Universal. Residindo em Pelotas, foi eleito vereador para o mandato 2000-2004. Está há um ano na Igreja Internacional, onde seu irmão ocupa o cargo de presidente desta igreja no Rio Grande do Sul. No horário eleitoral gratuito lembrou a sua condição de pastor: "atuei em várias cidades como pastor", sem mencionar, porém, a instituição religiosa.

Outra igreja que nas eleições de 2006 apresentou um membro seu como candidato a deputado estadual foi a Evangélica Pentecostal Cristã. O seu bispo Volmar Santos,

\footnotetext{
${ }^{5}$ Segundo suas palavras: "Pela construção de um hospital evangélico universitário. Pela construção de escolas com universidades evangélicas (...), vem comigo".

${ }^{6}$ De fato, por ocasião da propaganda eleitoral obrigatória no rádio e na televisão, Uberani Barbosa dizia ser "O único candidato indicado pela Igreja do Evangelho Quadrangular". Acrescentava ter sido vereador em Cruz Alta e em Cachoeira do Sul.

${ }^{7}$ Por ocasião da propaganda eleitoral obrigatória na mídia, Rogério Santos referia-se ao seu pai, nestes termos: "Aprendi com meu pai, deputado Manoel Maria, que política se faz com ética, respeito e responsabilidade".
}

Debates do NER, Porto Alegre, Ano 7, N. 10, P. 7-26, jul./Dez. 2006 
vereador na cidade de Dom Pedrito, obteve 5.990 votos. Esta é uma igreja gaúcha, fundada em 1955, em São Gabriel, por Marino Prudêncio Moreira, que desde 1986 se proclama bispo. Trata-se de uma igreja que pode ser inserida nas chamadas "empresas de cura divina" (Alves, 1988) ${ }^{8}$.

Também parece ser a primeira vez, no Rio Grande do Sul, que comparecem candidatos a deputados das igrejas Brasil para Cristo, Apostólica do Brasil e Sara Nossa Terra. Nenhum deles foi eleito. Os três representantes dessas igrejas proclamaram no horário eleitoral gratuito a condição de pastor, sem mencionar, porém, as suas igrejas.

\section{Candidatos Evangélicos Históricos à Assembléia Legislativa}

As principais igrejas evangélicas históricas têm representação no Rio Grande do Sul e alguns de seus membros compareceram como candidatos à Assembléia Legislativa, como se pode ver na Tabela III. Nenhum deles, porém, foi eleito.

Tabela III - Candidatos Evangélicos His tór icos - Assembléia Legislativa

\begin{tabular}{|c|c|c|c|c|c|}
\hline Denominação & Nome & Função & Partido & Votos & Situação \\
\hline $\begin{array}{c}\text { Confissão } \\
\text { Luterana }\end{array}$ & Luiz Artur & Pastor & PTB & 3.737 & Não-eleito \\
\hline Adventista & Elias Vidal & Pastor & PPS & 15.866 & Não-eleito \\
\hline Batista Filadélfia & $\begin{array}{c}\text { Cláudio } \\
\text { Conceição }\end{array}$ & Membro & PSDB & 5.681 & Não-eleito \\
\hline Batista Filadélfia & Airton Souza & Membro & PSDB & 17.088 & Não-eleito \\
\hline Batista & Irmão Bueno & Membro & PSDB & 353 & Não-eleito \\
\hline Presbiteriana & Argeu Brum & Membro & PSDB & 1.475 & Não-eleito \\
\hline Total & & & & 44.200 & \\
\hline $\begin{array}{c}\text { Outros } \\
\text { Evangélicos }\end{array}$ & & & & & \\
\hline- & Paulo Gonçalves & Pastor & PMDB & 2.871 & Não-eleito \\
\hline- & Cleber Cabral & - & PHS & 367 & Não-eleito \\
\hline Total & & & & 3.238 & \\
\hline Total Geral & & & & 47.438 & \\
\hline $\begin{array}{c}\text { Total Geral } \\
\text { Evangélicos }\end{array}$ & & & 198.248 & \\
\hline
\end{tabular}

${ }^{8}$ Para mais informações sobre a Igreja Evangélica Pentecostal Cristã ver Oro, 1990.

Debates do NER, Porto Alegre, ANo 7, N. 10, p. 7-26, Jul./Dez. 2006 
Como se pode ver, a maior votação foi alcançada pela Igreja Batista Filadélfia9. Juntos, os candidatos Airton Souza e Cláudio Conceição obtiveram 22.769 votos. O primeiro é membro da igreja há 23 anos e presentemente é vereador na cidade de Canoas. No horário eleitoral gratuito apresentava-se como sendo "um homem com valores em Deus, presidente voluntá rio da escola comun itária Vó Maria, que aten de 370 crianças por dia”. O segundo foi duas vezes candidato a vereador por Porto Alegre: em 2000, quando fez 1.949 votos, e em 2004, quando alcançou 3.588 votos. Naquelas oportunidades, como agora, repete no horário eleitoral o slogan "Deus é fiel".

A segunda igreja a obter o maior número de votos foi a Adventista do Sétimo Dia. Seu pastor, Elias Vidal, alcançou 15.866 votos. Atualmente ocupa uma cadeira na Câmara Municipal de Porto Alegre, tendo sido eleito em 2004, pelo PTB, com 5.541 votos. Anteriormente, nas eleições de 2000, Elias Vidal já havia obtido, sempre pelo PTB, 5.116 votos, para a Câmara Municipal, não tendo sido eleito, na ocasião. Na propaganda eleitoral gratuita não declarou o seu vínculo com a igreja. Centrou-se no tema das drogas: "Ame a vida e deixe as drogas", re petia.

As demais igrejas evangélicas históricas referidas tiveram um membro de suas fileiras concorrendo a uma cadeira na Assembléia Legislativa, mas obtiveram votaçóes insuficientes para serem eleitos. Luiz Artur exerce o segundo mandato como presidente do Conselho da Igreja Evangélica de Confissão Luterana no Brasil. No horário eleitoral convocou a "sociedade civil a tomar a política em suas próprias mãos (pois) passou o tempo de esperar por salvadores da pátria”. Por seu turno, Argeu Brum, da Igreja Presbiteriana do Brasil, não referiu diretamente, no horário eleitoral gratuito, a sua condição religiosa. Mas, expressou a sua indignação contra a corrupção. Dizia no horário eleitoral gratuito: "Chega de nos roubarem. Vote pela moralização no uso dos recursos públicos”. Enfim, Irmão Bueno, da Igreja Batista, dizia-se presidente e fundador da ONG Planejando do futuro e no horário eleitoral gratuito afirmou a necessidade do planejamento familiar.

\section{Candidato Católico à Assembléia Legislativa}

A Igreja Católica não estimula os membros do clero a se apresentarem como candidatos a cargos eletivos. Isto não significa, como se sabe, que esta instituição religiosa se

\footnotetext{
${ }^{9}$ Segundo Daltro Keidann, a Igreja Batista Filadélfia foi organizada, em Porto Alegre, no dia 5 de fevereiro de 1956, pelo pastor Astrogildo Pacheco. Segundo Keidann,

"Nessa ocasião, um grupo de 120 irmãos membros da Igreja Evangélica Batista Bethel, situada na Avenida Benjamin Constant, n. 1653, no bairro Floresta, ligado à Convenção das Igrejas Batistas Independentes, decidiram sair, junto com seu pastor, o mesmo Pastor Astrogildo Pachedo, depois de uma crise administrativa com o então missionário da Missão de Orebro, Robert Wilderson. Depois de algum tempo em oração, o grupo decidiu organizar a Igreja Batista Filadélfia, tendo como lema: "Amor do Irmão" (Keidann, 2006, pp. 200-201).
} 
mantenha alheia aos momentos eleitorais. O fato de a cada nova eleição a Conferência Nacional dos Bispos do Brasil (CNBB) divulgar um documento, às vezes na forma de "cartilha”, é u ma demonstração do seu interesse pelo político.

Neste ano de 2006, no mês de abril, a CNBB lançou o documento "Eleições 2006. Orientações da CNBB", o qual foi discutido pelo Cons elho Episcopal Pastoral da en tidade, assim como pelo seu Conselho Permanente, entre os dias 21 e 24 de março do mesmo ano $^{10}$. Trata-se, como se pode ler na sua introdução, de um "instrumento de trabalho", dirigido tanto aos eleitores, "incentivando a sua efetiva participação na escolha de seus representantes, apres entando-lhes alguns critérios de discernimen to", quanto aos can didatos, "apresentando-lhes propostas para a construção de políticas estruturantes, que assegurem o desenvolvimen to da nação com inclusão e justiça social".

Aos eleitores, alerta o documento, importa escolher os candidatos levando "em consideração tanto a honestidade pessoal, quanto a sua trajetória, voltada aos interesses da coletividade" (CNBB, 2006, p. 20). Além disso, "é preciso prestar muita a tenção nos candidatos despreparados, cujas plataformas camuflam interesses particulares (bem como) desconfiar de candidatos sustentados por campanhas financeiras vultosas que facilitam a compra de votos..." (Id. Ibid., p. 21). Ao contrário disso, "é importante conhecer os candidatos (...): quem são eles, sua origem política, o que já realizaram em prol da população, qual é a sua história, quais são suas propos tas..." (Id. Ibid).

Aos candidatos, preconiza o documento, cumpre primar "pelos compromissos honrados, sempre em estrita ligação com as necessidades reais da população. A transparência na gestão nunca lhes permite o expediente promíscuo na gestão do bem público, como se fosse um bem particular" (Id. Ibid.).

Apesar da ressalva quanto a candidaturas de membro do clero, como dissemos acima, nas eleiçôes 2006 no Rio Grande do Sul, ao menos um sacerdote se apresentou como candidato à Assembléia Legislativa, como resume a tabela IV.

Tabela IV - Candidato Católico - Ass embléia Legislativa

\begin{tabular}{|c|c|c|c|c|}
\hline Nome & Função & Partido & Votos & Situação \\
\hline Sadi Cordeiro & Padre & PV & 2.191 & Não-eleito \\
\hline
\end{tabular}

Em suas inserçōes no horário eleitoral gratuito Padre Sadi proclamava: "Vamos limpar a política". Também propunha a redução dos salários dos políticos e a realização de uma política social para os catadores de papéis, segundo ele, "os maiores ecologistas do mundo".

${ }^{10} \mathrm{O}$ documento contém 32 páginas e é formado por sete capítulos e dois anexos. Os capítulos recebem os seguintes títulos: I. Introdução: comprometidos como Igreja; II. Desafios do contexto atual; III. Sinais de resistência e esperança; IV. Ética na ação política e formação de consciência; V. As grandes opções do projeto de nação; VI. Critérios para a escolha dos candidatos; e VII. Orientações para a ação. Os anexos são os seguintes: 1. Funções dos Poderes Legislativo, Executivo e Judiciário; 2. Como formar Comitês da lei n. 9840/99.

Debates do NER, Porto Alegre, ano 7, N. 10, p. 7-26, jul./Dez. 2006 
Uma rápida olhada sobre as eleições que ocorreram nos últimos tempos mostra que nas eleiçôes proporcionais de 2000 houve também um sacerdote católico que se apresentou como candidato a vereador por Porto Alegre, não tendo sido eleito (Oro, 2003). Já nas eleições majoritárias de 2002, no Rio Grande do Sul, dois membros do clero católico se candidataram à Assembléia Legislativa, ambos pelo PT. O então deputado e sacerdote Roque Grazziotin, que nas eleições de 1998 havia feito 29.113 votos, nas eleiçōes de 2002 obteve 23.409 votos, ficando na segunda suplência; e Sérgio Goergen, eleito com 44.633 votos. Sérgio é membro da Ordem dos frades Menores da Província do Rio Grande do Sul e durante o governo Olívio Dutra, do PT (1998-2002), trabalhou, por dois anos, na Secretaria da Agricultura como Coordenador da Reforma Agrária. Não se reapresentou como candidato nas eleiçóes de 2006.

\section{CANdidatos AFro-Religiosos à Assembléta LegisLativa}

Dois candidatos compareceram ao pleito visando alcançar o legislativo estadual contando com votos do meio religioso afro-brasileiro. Um é pai-de-santo e outro é deputado do PT que atua na defesa de minorias religiosas e étnicas, sendo simpatizante das religiōes afro-brasileiras.

Tabela V - Candidatos afro-religiosos - Assembléia Legislativa

\begin{tabular}{|c|c|c|c|c|}
\hline Nome & Função & Partido & Votos & Situação \\
\hline Toni de Oxalá & Pai-de-santo & PTB & 1.731 & Não-eleito \\
\hline Edson Portilho & simpatizante & PT & 28.292 & Não-eleito \\
\hline Total & & & 30.023 & \\
\hline
\end{tabular}

Pai Tony de Oxalá recebeu aproximadamente o número de votos que outros pais-desanto obtiveram em Porto Alegre enquanto candidatos a vereador ${ }^{11}$. Recordamos que nas eleições de 1998 o Pai-de-santo Ailton Albuquerque obteve 3.425 votos como candidato a deputado estadual. No horário eleitoral gratuito, Pai Tony dirigia-se diretamente aos "irmãos africanistas, umbandistas e quimbandeir os". Afirmava também que estes segmentos religiosos alcançam um milhão de membros no Estado. Reivindicou votos a seu favor questionando: "Até quando seremos representados na Assembléia Legislativa apenas por outras religiōes?”. Também acionou um argumento muitas vezes usado por outros candi-

${ }^{11}$ Por exemplo, em 2000, o pai-de-santo e candidato a vereador por Porto Alegre Jorge Verardi obteve 1.994 votos e, em 2004, 2.014 votos.

Debates do NER, Porto Alegre, Ano 7, N. 10, P. 7-26, Jul./Dez. 2006 
datos desse meio religioso, opondo-se aos pentecostais, sobretudo à Universal, que os atacam. Perguntava: "Até quando seremos chamados de pais-de-encosto?"12.

O deputado do PT Edson Portilho obteve 28.292 votos, insuficientes para reconduzilo à Assembléia Legislativa. Nas últimas eleições obteve o apoio explícito de parcela de adeptos das religiôes afro-brasileiras do Estado em razão de sua atuação sobretudo na luta levada a efeito nos últimos três anos pelo segmento religioso afro-brasileiro contra a tentativa de implantaçãode uma legislação estadual contrao sacrifício de animais ${ }^{13}$. Apresentou-se no horário eleitoral gratuito como professor e deputado que luta pela "valorização da educação, a defesa dos direitos dos trabalhadores e aposentados e pela igualdade racial, por mais emprego, mais saúde e mais segurança”. Finalizava a sua apresentaçao com a ex pressão discursiva que expóe o seu alinhamen to com o campo afro-religioso. Dizia: "Muito axé".

\section{Candidatos Evangélicos à Câmara Federal}

No Rio Grande do Sul, nas eleiçôes de 2006, apresentaram-se 13 evangélicos como candidatos a deputados federais, sendo 6 da Assembléia de Deus, 1 da Universal, 3 da Quadrangular, 1 da Sara Nossa Terra ${ }^{14}, 1$ da Igreja Batista Betel e 1, ao que parece, atualmente sem vínculo denominacional definido.

A tabela VI apresenta o quadro geral dos candidatos evangélicos à Câmara Federal.

Tabela VI - Candidatos Evangélicos - Câma ra Federal

\begin{tabular}{|c|c|c|c|c|c|}
\hline Denominação & Nome & Função & Partido & Votos & Situação \\
\hline $\begin{array}{c}\text { Assembléia } \\
\text { de Deus }\end{array}$ & Paulo Eliseu & Evangelista & PSDB & 5.858 & Não-eleito \\
\hline $\begin{array}{c}\text { Assembléia } \\
\text { de Deus }\end{array}$ & Salvador & Presbítero & PP & 2.777 & Não-eleito \\
\hline $\begin{array}{c}\text { Assembléia } \\
\text { de Deus }\end{array}$ & Roberto Nogueira & Pastor & PTB & 21.558 & Não-eleito \\
\hline $\begin{array}{c}\text { Assembléia } \\
\text { de Deus }\end{array}$ & Nelson Souza & Evangelista & PTB & 3.926 & Não-eleito \\
\hline
\end{tabular}

${ }^{12}$ Esta é uma expressão depreciativa utilizada nos últimos anos na Igreja Universal para se referirem aos agentes religiosos das religiōes afro-brasileiras.

${ }^{13}$ Sobre este tema, e os embates que suscitou no Rio Grande do Sul e no país, ver Oro, 2005; Ávila 2006.

${ }^{14}$ A título informativo, o fundador e bispo presidente da Igreja Sara Nossa Terra, Bispo Rodovalho, foi eleito deputado federal pelo Distrito Federal, pelo PFL, com 68.378 votos. Concorreu pela primeira vez à Câmara Federal e foi uma dos mais votados. 


\begin{tabular}{|c|c|c|c|c|c|}
\hline $\begin{array}{c}\text { Assembléia } \\
\text { de Deus }\end{array}$ & Francisco Pacheco & Pastor & PAN & 1.700 & Não-eleito \\
\hline $\begin{array}{c}\text { Assembléia } \\
\text { de Deus }\end{array}$ & Milton Cárdias & Pastor & PTB & 14.262 & Não-eleito \\
\hline $\begin{array}{c}\text { Total de votos } \\
\text { Assembléia } \\
\text { de Deus }\end{array}$ & & & & 50.081 & \\
\hline Universal & Paulo Roberto & Bispo & PTB & 84.125 & Eleito \\
\hline Quadrangular & Reinaldo Santos & Pastor & PTB & 33.930 & Não-eleito \\
\hline Quadrangular & João Tardeti & Obreiro & PSB & 9.392 & Não-eleito \\
\hline Quadrangular & Nilo Santos & Pastor & PTB & 5.155 & Não-eleito \\
\hline $\begin{array}{c}\text { Total de votos } \\
\text { Quadrangular }\end{array}$ & Eloi Aires & Pastor & PSDC & 692 & Não-eleito \\
\hline Sara Nossa Terra & & & & 183.375 & \\
\hline $\begin{array}{c}\text { Total de votos } \\
\text { Pentecostais }\end{array}$ & Paulo Gouvêa & Pastor & PL & 7.724 & Não-eleito \\
\hline Outra & Cláudio Falcão & Evangelista & PHS & 1.712 & Não-eleito \\
\hline Igreja Betel & & & 192.811 & \\
\hline $\begin{array}{c}\text { Total de votos } \\
\text { Evangélicos }\end{array}$ & & & & 48.477 & \\
\hline
\end{tabular}

Excetuando um, todos os demais candidatos evangélicos à Câmara Federal são oriundos de igrejas pentecostais. Dos 13 candidatos somente 1 deles logrou ser eleito, o bispo Paulo Roberto, da Igreja Universal, que concorreu pelo PTB e obteve 84.125 votos. De forma semelhante ao candidato da igreja a deputado estadual, que apelava para a renovaçáo na Assembléia Legislativa, por ocasião da campanha eleitoral gratuita no rádio e na televisão Paulo Roberto afirmou: "precisamos combater a corrupção através da renovação".

Entre os 13 candidatos, 2 deles já eram deputados federais, eleitos no pleito anterior. Trata-se dos pastores Milton Cárdias, da Assembléia de Deus, e Reinaldo Santos, da Igreja Quadrangular. Ambos foram eleitos nas eleiçōes de 2002, o primeiro com 40.820 votos e o segundo com 43.716 votos. Nas eleiçóes de 2006 o primeiro aparecia na mídia eleitoral efetuando o seguinte pronunciamento: "Amigos e irmãos em Cristo, sou deputado federal e pastor Milton Cárdias. Tenho trabalhado pelo desenvolvimento dos pequenos municípios eem projetos de geração de emprego e rend a. Busco novamente o seu apoio". O segundo dizia-se "deputado da família, defendo a valorização e o fortalecimento da base da sociedade. Represento os cristãos evangélicos do Rio Gran de (...) Vote pastor Reinaldo”.

A tabela VI ainda mostra que o somatório dos votos distribuídos entre os 6 candidatos da Assembléia de Deus chegou a 50.081 votos, enquanto que o somatório dos votos da Quadrangular foi de 48.477 votos. Se, como se pode deduzir, as duas instituições evangélicas em questão tivessem concentrado seus votos em um único candidato teriam tido êxito. Foi o que fez a Universal. Isto mostra não somente as diferenças de gestão organizativa 
existente entre essas igrejas pentecostais mas também as diferenças de percepção quanto à participação dos fiéis na política.

Além disso, a tabela VI mostra que a votação do deputado federal Paulo Gouvêa foi de 7.724 votos. Este deputado foi até recentemente pastor da Igreja Universal, tendo sido destituído dessa função pela igreja e por ela preterido quando seu nome apareceu no escândalo dos "Sanguessugas". Enquan to pastor da Universal e apoiado massivamente por esta igreja, Paulo Gouvêa tinha ganho duas eleições, a última com a expressiva votação de 103.959 votos. Agora, abandonado pela Universal obteve pouco mais de sete mil votos.

Entre os demais candidatos à Câmara Federal da Assembléia de Deus figuravam os seguintes: Paulo Eliseu, que nesta, como em outras duas tentativas a cargos eleitorais ${ }^{15}$, se apresentou na mídia dizendo-se "evangelista da Assembléia de Deus e assessor parlamentar por vários an os"; Salvador, que no horário eleitoral apelou ao eleitor para juntos combaterem a corrupção: "Você e eu juntos para lutar e combater a máfia da corrupção (...) Que nosso Deus soberano abençõe nossas famílias e ilumine nosso caminho"; Nelson Souza, que veiculou a sua condição de membro da Assembléia de Deus: "Sou evangelista da Assembléia de Deus e vereador e líder do PTB na câmara de Viamão”; e o pastor Francisco Pacheco, que também usou o tema da corrupção como mote da sua propaganda: "Te convido para nos ajudar a limpar a Câmara dos Deputados e deixar para os nossos filhos o orgulho de ter sido honesto".

Relativamente aos candidatos à Câmara Federal da Igreja do Evangelho Quadrangular, além do pastor Reinaldo Santos concorre ram Nilo Santos e João Tardeti. O primeiro também explorou, ainda que indiretamente, o tema da ausência de ética na política. Disse ele na propaganda eleitoral gratuita: "Quero trabalhar com simplicid ade e hones tidade, pois é iss o que o Brasil precisa hoje”. Por seu tu rno, João Tardeti, obreiro da igreja e vereador em Cachoeirinha, apelou para a unidade do "povo cristão". Disse ele: "Convido todo povo cristão para mostrar nossa unidade. Com fé transformaremos o país".

Enfim, o pastor Eloi Aires, candidato a deputado federal pela Igreja Sara Nossa Terra, e residente em Santa Maria, apelou aos eleitores de todas as religiōes: "Amigos de todas as religiōes! Meu lema é Deus, pátria e família. Eu sou o Pastor Eloi Aires”. E o evangelista da Igreja Batista Betel Cláudio Falcão apelou para a honra dos gaúchos: "Falo a todos os gaúchos que tem caráter e vergonha na cara. Serei o teu representante para defender os direitos do nosso Estado, e que Deus abençoe nosso Rio Grande”.

\section{Candidato CATÓlico a Deputado FEDERAL}

O único candidato que abertamente se declara católico a participar no pleito de 2006 como candidato a deputado federal foi João Carlos Nedel. A tabela a seguir circunscreve-se a ele.

${ }^{15}$ Concorreu nas duas ultimas eleiçóes, para deputado estadual e para vereador em Porto Alegre.

Debates do NER, Porto Alegre, ANo 7, N. 10, P. 7-26, JUl./DeZ. 2006 
Tabela VII - Candidato Católico - Câmara Federal

\begin{tabular}{|c|c|c|c|c|}
\hline Nome & Função & Partido & Votos & Situação \\
\hline João Carlos Nedel & Membro & PP & 16.720 & Não-eleito \\
\hline
\end{tabular}

Nedel é vereador em Porto Alegre, exercendo seu mandato de 2005 a 2008. Já concorreu, sem êxito, em duas oportunidades a uma vaga à Assembléia Legislativa do Estado. Tentou pela primeira vez uma cadeira na Câmara Federal. Em todas as vezes em que disputou algum cargo eletivo expressou a sua condição de político cristão, defensor da ética e contra a corrupção. Também desta feita disse: "Como cristão e político, minha ação é marcada pelo respeito à ética e contra a corrupção". A votaçáo que obteve nas últimas eleiçôes foi a maior já alcançada em sua carreira política.

Passemos agora à segunda parte do texto, que visa relacionar as continuidades verificadas entre as eleições passadas e a atual, bem como as especificidades observadas no pleito que acaba de se realizar.

\section{RELIGIÃO E ELEIÇÃO 2006: CONTINUIDADES E NOVIDADES EM RELAÇÃO AOS PLEITOS ANTERIORES}

No que tange às instituições religiosas e candidatos religiosos ou representantes de segmentos religiosos nas eleições de 2006 no Rio Grande do Sul, a recorrência mais significativa a ser destacada é a eficácia da Igreja Universal, já demonstrada por ocasião das eleições proporcionais de 2000 e de 2004 em Porto Alegre, e das majoritárias de 2002 e agora de 2006, no Estado ${ }^{16}$. Em todas essas eleiçôes, a Universal conseguiu eleger os seus candidatos ${ }^{17}$. Nesta última eleição, como nas anteriores, entrou em ação a "máquina iurdiana” que garantiu novamente a eleição dos candidatos escolhidos e apoiados pela Igreja, tanto a nível estadual quanto federal. Isto comprova mais uma vez, como já foi dito (Oro, 2003), a eficácia do carisma institucional iurdiano.

\footnotetext{
${ }^{16}$ Como se sabe, isto não é algo específico do Rio Grande do Sul. Há um reconhecimento, já observado por vários autores, da eficácia política da Igreja Universal que, por sua vez, se inscreve num contexto maior de eficácia, que faz desta "uma igreja de sucesso" (Oro, Corten e Dozon, 2003; Freston, 2000).

${ }^{17}$ Por exemplo, em 2000, a Universal apresentou dois pastores como postulantes à vereança pelo município de Porto Alegre. Ambos foram eleitos, Valdir Caetano, com 10.913 votos, e Almerindo Filho, com 7.645. Nas eleiçōes de 2004, ambos foram reeleitos, o primeiro com 10.138 votos e o segundo com 6.342 votos. Para a Assembléia Legislativa do Estado, a Universal apresentou em 1998 como candidato o pastor Paulo Moreira, que foi eleito. Em 2002, como já dissemos, apresentou o pastor Sergio Peres, também eleito.
} 
De fato, reproduziu-se novamente a escolha da "candidatura oficial" da igreja, por parte do seu grupo dirigente - sem qualquer participação dos fiéis em geral - e a ação de todos os membros da hierarquia, bispos, pastores, pastores auxiliares, como também de obreiros, e mesmo de fiéis, nos templos e nas mídias da igreja, assim como nas ruas, visando divulgar os nomes dos candidatos e incentivar os fiéis a votarem neles. Reproduziu-se também um discurso de motivação simbólica, visando fortalecer a necessidade dos membros ou simpatizantes da igreja de votarem nos candidatos escolhidos, indicados, pelos dirigentes da Igreja, postos que são tidos como "valentes do senhor", "homens de Deus", que terão a missão de zelar pelos valores cristãos no âmbito do político. Enfim, reproduziu-se novamente a situação segundo a qual a retirada do apoio institucional da igreja para alguém que já havia sido eleito anteriormente, significa o seu fracasso eleitoral. Foi, desta vez, o que ocorreu com o deputado federal Paulo Gouvêa, como vimos acima.

A nosso juízo, a principal recorrência observada nas eleições de 2006 se circunscreveu à Igreja Universal. Isto porque, em relação às demais instituições religiosas transpareceu sobretudo especificidades atuais, se comparadas com as eleiçôes precedentes. Elas dizem respeito tanto às igrejas Assembléia de Deus quanto Quadrangular.

De fato, nas eleições de 2002, e em outras, a Assembléia de Deus do Rio Grande do Sul havia adotado o modelo de escolha prévia, realizada entre os pastores da instituição, de can didatos tidos como "oficiais" da igreja, não impedind o, porém, que outros cidadãos da igreja também se apresentassem como candidatos. Mesmo assim, como dissemos, essa igreja pentecostal logrou eleger como deputado estadual, em quatro oportunidades, o pastor Edemar Vargas, e na eleição de 2002, o pastor Milton Cárdias, para deputado federal.

Ora, nesta última eleição, a igreja não apresentou candidatos oficiais. Como conseqüência disso, apresentaram-se 15 candidatos, 9 para deputado estadual e 6 para deputado federal, todos dizendo-se representantes ou membros da Assembléia de Deus, procurando buscar nesse meio sócio-religioso parte significativa dos seus votos. E em certa medida foi o que ocorreu, pois distribuíram entre si os votos ali existentes, não elegendo nenhum deles.

Essa nova postura da Assembléia de Deus nas eleiçoes de 2006 resultou,ao que consta, da conjunção de dois fatores. $\mathrm{O}$ primeiro diz respeito à diferença de percepção da relação entre religião e política tida entre o presidente anterior e o atual presidente da Assembléia de Deus do Rio Grande do Sul, este último sendo mais reticenteem relação à aproximação dessas instâncias sociais. $\mathrm{O}$ segundo deriva de um certo desencantamento pelo político observado nos últimos meses no meio assembleiano, posto que os fiéis se dão conta de que muitas vezes colocam na instância política os seus melhores quadros religiosos que, porém, uma vez no exerácio do mandato realizam uma prestação política quase insignificante e de pouca visibilidade. Assim sendo, por um lado, sentem-se privados de bons pastores e, por outro, não percebem mudanças na política em geral que continua como sempre esteve, ou seja, segundo eles, privada de ética e de valores cristáos, contrariamente à expectativa gerada nesse meio religioso com a eleiçáo de políticos oriundos do meio evangélico em geral, e assembleiano em partiaular ${ }^{18}$.

\footnotetext{
${ }^{18}$ Esse desencantamento com a política vigente no meio assembleiano, que poderia culminar com a desmobilização política dessa instituição religiosa, já havia sido prevista por Oro em comunicação realizada em 2005, em Paris (Oro, 2005).
}

Debates do NER, Porto Alegre, ANo 7, N. 10, P. 7-26, JUl./DeZ. 2006 
Outra mudança significativa foi percebida no âmbito da Igreja do Evangelho Quadrangular. Em eleiçōes anteriores para deputado estadual ela também realizou prévias internas à igreja, junto aos pastores e obreiros, e escolheu o seu candidato, o deputado Manoel Maria, em três oportunidades. Nas eleiçóes de 2002, além deste deputado para a Assembléia Legislativa, a igreja também realizou uma prévia para a Câmara Federal e indicou o pastor Reinaldo Santos como candidato. Da mesma forma que a Universal, nessas oportunidades, houve toda uma mobilização no interior da igreja para a conquista dos votos dos fiéis. E o êxito fora alcançado. Nas eleiçóes de 2006, porém, a igreja continuou a escolher os seus representantes "oficiais", mas surgiram vários outros ca ndidatos egressos da igreja que disputaram com eles os votos dos fiéis. O resultado, como vimos, pela primeira vez nesta igreja, foi a não-eleição de nenhum dos seus candidatos, tal como ocorreu com a Assembléia de Deus, uma vez que os votos foram distribuídos entre os vários candidatos.

Como já dissemos acima, além dessas particularidades sobressaiu também, nas eleiçôes de 2006, no Rio Grande do Sul, a presença da diversidade evangélica, sobretudo pentecostal, na postulação de cadeiras para a Assembléia Legislativa e para a Câmara Federal. As igrejas, Internacional da Graça, Brasil para Cristo, Sara Nossa terra, Evangélica Pentecostal Crista, marcaram presença e desencadearam uma certa competição entre si visando eleger representantes das respectivas denominações aos cargos eletivos.

\section{CONCLUSÃO}

O balanço da presença política dos candidatos religiosos, ou que mantém afinidade com segmentos religiosos, nas eleições 2006, no Rio Grande do Sul, pode ser considerado expressivo do ponto de vista do número de candidatos e de sua ampliação do leque de representação denominacional. Porém, pode também ser considerado um fracasso, se considerarmos o número de candidatos eleitos: somente um deputado estadual e um deputado federal. Lembramos que nas eleições de 2002 haviam sido eleitos cinco candidatos religiosos à Assembléia Legislativa do Estado e dois candidatos religiosos para a Câmara Federal ${ }^{19}$.

Com já dissemos, assistimos novamente a Igreja Universal impor a sua força política, elegendo os seus dois candidatos, um a deputado estadual e outro a deputado estadual. Esta igreja reproduziu, nas eleiçōes 2006, no Rio Grande do Sul, o mesmo modelo de prática política já testada exitosamente em outras oportunidades, prática esta assim resumida por André Marenco:

"A Universal revelou significativa capacidade de converter fiéis em eleitores, baseada em uma organização não apenas centralizada, como também capaz de no extremo de sua

\footnotetext{
${ }^{19}$ Reiteramos que se trata do Frade Capuchinho Sergio Goergen, dos pastores Manoel Maria, Edemar Vargas e Sergio Peres, além do evangelista Eliseu Santos. Os deputados federais eleitos foram os pastores Milton Cárdias e Reinaldo Santos.
}

Debates do NER, Porto Alegre, Ano 7, N. 10, P. 7-26, Jul./Dez. 2006 
rede, impermeabilizar seus seguidores contra a dispersão de votos, tanto entre seus candidatos como face a outros apelos, não apenas religiosos. As fracas votaçôes obtidas por candidatos de outras correntes religiosas sugerem sua fragilidade nesta direção, ou seja, encaminhar seus seguidores, do templo à urna" (Marenco, 2001, p. 108).

O êxito mais uma vez comprovado da Universal talvez tenha um efeito, como já dissemos em outras oportunidades (Oro, 2003), mais para dentro do campo religioso, posto que tende a produzir em outras denominações o desejo de imitação do "modelo iurdiano" defazer política. Já o efeito sobre o campo político propriamente dito, parece ser bastante reduzido. Isto porque, por um lado, os religiosos evangélicos eleitos tendem a passar por um processo de secularização, na medida em que vão ingressando no político institucional, como mostrou Marcio Santos em seu estudo sobre a prática política dos vereadores iurdianos na Câmara Municipal de Porto Alegre (Santos, 2005). Além disso, tais agentes religiosos eleitos estariam no político institucional agindo em nome das denominaçōes que os elegeram, atuando en quan to "despachantes" dasmesmas (Mariano, 2000), afirmando a sua presença coletiva, enquanto grupo de pressão política, somente em temas muito particulares, que concernem a ordem da moral sexual, opondo-se contra a união civil de homossexuais e contra a prática do aborto. Por outro lado, com destacou Renato Janine Ribeiro, embora tivessem intenção de intervir no político institucional, sucumbem diante dele, em razão da sua estrutura e poder organizacional legal. É esta força do político institucional que levou Renato Janine Ribeiro a considerá-lo uma "força vampirizadora (...) do que há de melh or na sociedade” (Ribeiro, 2002, pp. 104-105).

\section{REFERENNCIAS}

ALVES, Rubem. "A empresa da Cura Divina: um fenômeno religioso?” In: A cultura do povo. 4a. Ed. São Paulo, Cortez ed. 1988, pp. 111-118.

AVILA, Cíntia Aguiar de. "Apanijé". "Nós matamos para comer": uma análise sobre o sacrifício de animais nas religiōes afro-brasileiras. 2006. Trabalho de Conclusão de Curso (Graduação de Ciências Sociais). Universidade Federal do Rio Grande do Sul.

CONFERENCIA NACIONAL DOS BISPOS DO BRASIL (CNBB). Eleições 2006. Orientaçôes da CNBB, abril de 2006, 32 p.

FRESTON, Paul. The political evolution of Brazilian Pentecostalism, 1986-2000. In: CORTEN, André; MARY, André (orgs). Imaginaires politiques et Pentecôtisme: Afrique et Amérique. Paris, Karthala, 2000, pp. 287-306.

KEIDANN, Daltro Miguel. Batistas no Rio Grande do Sul. Uma introdução a sua história. Porto Alegre. Ed. Do Autor, 2006.

MARENCO, André. "Fides Implicita". Can didatos Religiosos nas eleições municipais de 2000 em Porto Alegre. In: Debates do NER, ano 2, N. 3, 2001, pp. 101-109. 
MARIANO, Ricardo. Islâmicose evangélicos na arena política. In: Veredas, Belo Horizonte, N. 1, agosto 2000, pp. 49-64.

ORO, Ari Pedro. Le Pentecôtisme et la politique au Brésil. Paper apresentado no Congresso Inter nacional "Champ religieux brésilien: les apports de la socio-anthropologie". Maison de l'Amérique latine. Paris, 6-7 dezembro de 2005.

ORO, Ari Pedro. "Religiōes pentecostais e meios de comunicação de massa no sul do Brasil”. In: Revista Eclesiástica Brasileira. N. 198, junho 1990, pp. 304-334.

ORO, Ari Pedro. Religião e eleiçōes 2000 em Porto Alegre. In: Debates do NER, ano 2, N. 3, Porto Alegre, PPGAS, 2003, pp. 9-70.

ORO, Ari Pedro. A política da Igreja Universal e seus reflexos nos campos religioso e político brasileiros. In: Revista Brasileira de Ciências Sociais. V. 18, N. 53, outubro de 2003, pp. 53-70.

ORO, Ari Pedro. O sacrifício de animais nas religiōes afro-brasileiras: analise de uma polêmica recente no Rio Grande do Sul. In: Religião e Sociedade. V. 25, N. 2, 2005, pp. 11-31.

ORO, Ari Pedro; CORTEN, André; DOZON, Jean-Pierre. Igreja Universal do Reino de Deus. São Paulo, Ed. Paulinas, 2003.

PRANDI, Reginaldo. Os candomblés de São Paulo. São Paulo, Hucitec, 1991.

RIBEIRO, Renato Janine. Religião e politica no Brasil contemporâneo. In: FRIDMAN, Luis Carlos (org). Política e Cultura. Século XXI. Rio de Janeiro, ALERJ, Relume Dumará, 2002, pp. 99-110.

SANTOS, Márcio Martins dos. "Tributos do povo, servos de Deus": Um estudo antropológico sobre políticos e religião na cidade de Porto Alegre. 2005. Dissertação (Mestrado em Antropologia Social). Universidade Federal do Rio Grande do Sul, Porto Alegre, 2005.

STEIN, Luciano. Coração missionário. A vida e a obra de Nils e Mary Taranger. Porto Alegre, Ed. Esperança, 1998. 